\title{
Drogadição na contemporaneidade: Pessoas, famílias e serviços tecendo redes de complexidade
}

\author{
Drug addiction in the contemporary word: People, families \\ and institutions weaving nets of complexity
}

\author{
Mara Regina Soares Wanderley Lins ${ }^{[a]}$, Helena Beatriz Kochenborger Scarparo ${ }^{[b]}$
}

\footnotetext{
[a] Docente e supervisora do Centro de Estudos da Família e do Indivíduo (CEFI), Mestre em Psicologia Social pela Pontifícia Universidade Católica do Rio Grande do Sul (PUCRS), com apoio da CAPES, Porto Alegre, RS - Brasil, e-mail: mararswlins@gmail.com

[b] Professora Doutora em Psicologia do Programa de Pós-Graduação da Faculdade de Psicologia da Pontifícia Universidade Católica do Rio Grande do Sul (PUCRS), Porto Alegre, RS - Brasil.
}

\section{Resumo}

As características da sociedade contemporânea corroboram a ideia de que o aumento da drogadição é um sintoma dos atuais modos de vida, pautados pela urgência e pelo consumo. Mesmo assim, trata-se de um problema de saúde pública, com alto custo social, traduzido em internações psiquiátricas, acidentes de trânsito, variadas formas de violência, prisões, ausências no trabalho e na escola. Como a família constitui a fonte de socialização primária, é possível dizer que, além de ser afetada pela drogadição, ela pode facilitar e perpetuar seus processos. Para compreender esse fenômeno, este artigo apoia-se no paradigma da complexidade proposto por Edgar Morin. Primeiramente, aborda-se a complexidade da drogadição na contemporaneidade, articulando produções científicas aos principais operadores do pensamento complexo. Depois, associam-se a essas reflexões questões relativas à família e à constituição de redes, e a ligação se estabelecerá agregando questões das políticas públicas quando tratam do tema.

Palavras-chave: Drogadição. Família. Políticas públicas. Complexidade.

\begin{abstract}
The caracteristics of contemporary society confirm the idea that the increase of drug addiction is a symptom of the lifestyle from our times, which is ruled by urgency and consume. Even so, we should consider it a problem concerning public health, with great social cost, such as psychiatric hospitalization, traffic accidents, several types of
\end{abstract}


violence, imprisonment, work's and school's absence. As the family is the source of primary socialization, we may say that besides being affected by drug addiction, the family may facilitate and perpetrate its processes. This paper aims to reflect on the complexity proposed by Edgar Morin as a support to understand this phenomenon. Firstly, it will talk about the complexity of drug addiction in the contemporary world, articulating scientific production to the main users of the complex thought. After that, it will associate to these reflections issues related to the family, the constitution of nets, and the link will be established by the association of issues from public policies concerned to this theme.

Keywords: Drug addiction. Family. Public policies. Complexity.

\section{Introduçáo}

Temáticas que integram família, políticas públicas e substâncias psicoativas (SPA) são rotineiras tanto no senso comum como nas práticas profissionais e acadêmicas. Em função disso, são focos de discussões, de promessas em plataformas políticas e de planos de gestão. Entretanto, quanto mais se discute o assunto, mais ele se mostra campo de difícil intervenção, controvertido e repleto de nuances. Isso implica encontrar problematizações, silêncios, interdições e reticências que, associadas aos fenômenos que engendram, justificam exames críticos e rigorosos do assunto.

Diante da multiplicação de problemáticas que nos apresenta a drogadição, muitas das teorias disponíveis não possibilitam integração da diversidade de dados, posicionamentos e contradições que caracterizam as relações entre família, políticas públicas e drogadição. São comuns os descompassos entre abordagens teórico-metodológicas utilizadas para tratar do tema e o modo como os fenômenos associados a ele se manifestam. Optou-se aqui, então, por uma compreensão múltipla e multidimensional do fenômeno, considerando contradições, incertezas e desordens como parte da construção do conhecimento. O pensamento complexo oferece instrumentos para a construção de caminhos de compreensão desse processo. Trata-se da busca de alternativas às fragmentações que impedem a compreensão da globalidade dos fenômenos. São alternativas que propõem o resgate das relações sociais em movimentos de ampliação e atualização, na medida em que questionam visões simplificadoras da ciência e a dicotomização dos fenômenos (Morin, 1998, 2005). Assim, movimentos e compreensão dos fenômenos transcendem as esferas da racionalidade e dos centros de comando e decisão convencionais.
Envolvem também "interações espontâneas entre grupos e indivíduos" (Morin, 1998, p. 181). Como decorrência, evidencia-se a necessidade de exercitar pensares que permitam ligar o que parece desarticulado: convenções-informalidade, razão-confusão, arte-cientificidade, saber-ignorância, preparaçãoespontaneidade, intimidade-estranhamento... Dentre os conceitos fundamentais para o presente estudo, sobressaem-se especialmente os operadores dialógico, recursivo e hologramático propostos por Morin (1998). Organizamos o texto priorizando relações entre o tema estudado e esses operadores.

\section{Complexidade, drogadição e tempo presente}

Não é novidade que o uso de substâncias psicoativas acompanha a história da humanidade, pois se trata de prática cujas origens remontam à pré-história (Minayo, 2003). O uso obedecia a uma gama variada de objetivos, dentre esses, destacam-se os lúdicos, os rituais místicos, as intencionalidades religiosas e a aplicação medicinal (MacRae, 2001). Com o processo de industrialização e crescimento do capitalismo, passaram a existir disputas de diferentes categorias profissionais, como médicos, farmacêuticos, fabricantes de remédios, herbolários e praticantes da medicina popular. O ponto de discórdia situava-se em quem produziria e quem prescreveria as drogas, pois já estavam sendo vistas como fonte de renda e havia necessidade de fragmentação dos grupos envolvidos para delimitar e restringir a posse e, consequentemente, o lucro.

Percebe-se aqui a perspectiva hologramática, na medida em que permite a compreensão dos acontecimentos no contexto, a partir dos sujeitos implicados nesse processo. Esses eram parte e continham o todo. Suas normas, linguagens e 
representações traduziam-se no espírito do tempo que se voltava para a racionalização da ciência e para hegemonias profissionais.

Nos Estados Unidos da América, ocorreram medidas de contenção da produção e comercialização das SPA, motivadas por interesses políticos e econômicos que relegavam a saúde para segundo plano, contrariando discursos oficiais. Foi o caso da Lei Seca, que proibiu o uso de álcool de 1919 a 1932. Com o tempo, essa medida mostrou-se ineficaz e estimulou o tráfico, a violência e favoreceu o enriquecimento ilícito de quem produzia e vendia bebida alcoólica. Assim, ficou evidente que medidas de total repressão não diminuem o uso de SPA (Escohotado, 1994).

Cabe, então, indagar e propor processos dialógicos sobre condições que delimitam o uso de SPA como problema de saúde pública de grandes proporções (Baltieri \& Focci, 2001; Seibel \& Toscano Jr., 2001). Essa questão tem sido estudada, ampliando a literatura sobre o tema na tentativa de ter respostas apaziguadoras das incertezas do presente. Uma dessas tentativas associa o mundo globalizado à ideologia individualista, à intensificação do hedonismo e à massificação do consumo. O mundo contemporâneo vive esvaziamentos simbólicos da herança cultural. Surgem progressivos rompimentos da articulação entre passado, presente e futuro, gerando o eterno presente. A palavra de ordem do mundo globalizado é sedução, tendo o consumo como suporte e emblema característico (Saraiva, 2000).

Assim se estabelecem condicionamentos de necessidades numa teia de troca e produção de valores, na qual cada um e todos se acham enredados. Há um imperativo da diversão e da exploração de possibilidades de gozo. Podemos afirmar que, na contemporaneidade, não se usa drogas, mas se consome drogas, o que denota a relevância do viés econômico do fenômeno (Zemel, 2001).

Essas questões revelam estratégias de autoorganização. Morin (2007) refere-se ao homo sapiens como racional; acrescenta o faber, como aquele que fabrica e utiliza instrumentos; e o economicus, que complementa a razão com utilidade e interesse, característica da sociedade de consumo. Contudo, para o autor, essa especificidade permanece insuficiente ao ignorar a loucura, o afeto, o mitológico, o religioso, o imaginário, o lúdico, o estético. Assim, acrescenta à razão o homo demens, o qual representa a disposição humana para a hubris, que significa desmedida demente, o amor e o ódio, a imaturidade, a loucura. Vivemos circuitos de relações interdependentes e retroativas com um pólo sapiens e outro demens. É uma dialógica criadora e, ao mesmo tempo, destruidora, pois

na ruptura dos controles racionais, culturais, materiais, quando há confusão entre o objetivo e o subjetivo, entre o real e o imaginário, hegemonia de ilusões, insensatez, o bomo demens submete o homo sapiens e subordina a inteligência racional a serviço dos seus monstros (Morin, 2007, p. 127).

Nessa perspectiva, na contemporaneidade a drogadição favorece a negação e a sedação como modos de ratificar lógicas lineares de resolução de problemas. Tal lógica não considera a incerteza, nem a multidimensionalidade dos processos humanos. Assim, até mesmo adoecer pode ser entendido como resultado de um comportamento individual inadequado, um descuido com a saúde. Dessa forma, a dependência química pode ser vista como responsabilidade do indivíduo, o que fragmenta a compreensão do fenômeno. Então, as contradições continuam a ser produzidas socialmente, mas seus enfrentamentos são individualizados, ou seja, cada um deve assumir o próprio risco, absorvido em si (Bauman, 2001).

Essa posição impede a dialógica que possibilitaria juntar, por exemplo, individual e coletivo, público e privado, família e indivíduo, na produção de entrelaçamentos do fenômeno ao complexo (Morin, 2005). São perspectivas que enfocam o indivíduo para explicar as práticas humanas. Desse modo, responsabilizam isoladamente o dependente químico pelo uso de SPA, ao mesmo tempo em que, do ponto de vista recursivo, tal lógica reforça e legitima o paradigma moderno, assim como o sujeito da modernidade o corrobora e é produzido por essas perspectivas ao agir no mundo. Morin (2005) propõe a expressão homo consumans para tentar definir o homem da sociedade contemporânea. Este se refere ao fato de que carregamos um princípio de dilapidação e dissipação.

Assim, a toxicomania revela sintomas da sociedade de consumo (Minayo, 2003), que, no capitalismo pós-moderno, é percebida como disparadora e aceleradora da drogadição, pois o mercado das drogas oferece poder econômico e possui capilaridade, indo das camadas sociais mais pobres até 
as mais abastadas. O que é valorizado é o consumo, em que, além do abuso de substâncias psicoativas, percebe-se o abuso das relações e do meio ambiente.

As articulações com a esfera coletiva associam o fenômeno a questões macrossociais, o que, muitas vezes, confere a falsa perspectiva de totalidade às dimensões de classe, etnia, religiosidade e gênero. Tais categorias, na atualidade, têm sido ressignificadas na medida em que os processos de transnacionalidade e globalização têm provocado mudanças nas práticas sociais do tempo presente. Esses contextos são temas das reflexões de Gonçalves, Delgado e Garcia (2003), os quais entendem a pós-modernidade como novo estágio do sistema de produção do capitalismo, caracterizado por estimular o consumo e gerar exclusão e miséria. Nesse sentido, a racionalidade linear moderna cede lugar à dispersão dos saberes, à lógica da insegurança, à produção irrestrita de bens, com o cotidiano imerso no consumo, revelando-se um sistema gerador de sofrimento, desigualdades e, até, morte (Horta, 2003).

Ao relacionar essas questões com as políticas direcionadas ao problema das drogas, faz-se associação com o operador recursivo, que propõe inserir a família como mais uma das possíveis articulações, produtora e produto dos modos de vida pós-modernos. E, como pensar complexamente é "pensar e aceitar a contradição, confrontá-la e superála, sem negá-la e sem querer reduzi-la" (Vasconcellos, 2008, p. 116), entendemos o abuso de SPA como prática social. De certa forma, todos são usuários e abusadores: consome-se medicações para relaxar, despertar e suportar as angústias, usa-se bebidas alcoólicas para comemorar e espantar tristezas, são comuns comportamentos abusivos como excesso de comida, de trabalho, de exercícios físicos, de gastos, de tempo, excessos... Pode-se afirmar que, recursivamente, a família é, então, produto e produtora do uso abusivo de SPA, entendida, segundo Horta (2003), como modo de viver humano, que pode ser vista como uma instituição que muda ao longo dos tempos, um modo de regulação de vida em sociedade.

\section{Família e drogadiçáo na perspectiva da complexidade}

Etimologicamente, a palavra 'família' origina-se do latim famulus, que significa escravo, e até o século XV o termo era utilizado para se referir aos serviçais do dono de uma propriedade. A partir de então, seu significado foi ampliado, abarcando todos os membros da moradia (Sluzki, 1997). Presentemente, refletir sobre a definição de família implica ter em conta inúmeras transformações que caracterizam a contemporaneidade, que alteraram as relações interpessoais e, como decorrência, observase mudanças significativas nas composições dos sistemas familiares. Em função disso, Zimerman e Osório (1997) afirmaram tratar-se de um conceito polissêmico e multifacetado que assume diferentes modalidades de convivência humana - motivo pelo qual é mais viável descrevê-la do que conceituá-la.

Este artigo pretende considerar tal diversidade, na medida em que as famílias que enfrentam circunstâncias associadas à drogadição mostram-se extremamente vulneráveis. Do mesmo modo, os estudos acerca das relações entre família e drogadição apresentam conotações diversas: problema individual, questão social, fenômeno transgeracional, ferramenta de prevenção e/ou coadjuvante no uso e no tratamento. Pode ser tema de uma compreensão que transcende a dicotomia individual-coletivo e articula o assunto a temas globais que inserem o fenômeno da drogadição nos modos de ser, significar e conviver no tempo presente.

A influência da família na origem, no curso e nas consequências do uso é foco de interesse de estudos e pesquisas. Tal interesse parece se associar frequentemente à abordagem individualista do fenômeno, o que minimiza ou até mesmo exclui a responsabilidade sociocultural na determinação da drogadição. Os estudos que relacionam história familiar e uso abusivo de SPA dirigem-se, em sua maioria, para a detecção de fatores de risco, sendo necessário articulá-los com os outros fatores sociopolíticos e culturais. É o caso do estudo desenvolvido por Stanton e Todd (1998), segundo o qual a drogadição é o resultado de uma combinação de ausência de limites definidos contraposta a uma relação pautada pela simbiose emocional e superproteção. É comum, na história dos pais e mães de drogaditos e drogaditas, sofrimentos e responsabilidades precoces, os quais interferiram na capacidade de ocupar o lugar de cuidadores dos filhos (Cirillo, Berrini, Cambiaso \& Mazza, 1999).

Outros estudos referem o apego patológico na etiologia da drogadição, considerando o uso como modo de obtenção de equilíbrio familiar (Zemel, 2001; Bertolote \& Ramos, 1997). O curso 
da drogadição pode ser explicado pela participação da família no processo de prevenção, abstinência ou recaída do drogadito (Bucher, 1996; Craig, 1991; Feix, 1996; Bertolote \& Ramos, 1997). De acordo com os estudos consultados, é atribuída à participação familiar grande parcela no sucesso das intervenções propostas. Edwards e Dare (1999), ao questionar motivos da tolerância da conduta de um dependente químico pela família, observam que o tratamento deve incluir a família, pois ela também tem necessidades que precisam ser escutadas.

O segundo levantamento realizado pelo Centro Brasileiro de Informações sobre Drogas (Carlini, Galduróz, Nappo \& Noto, 2005) revelou que $78 \%$ dos não usuários de SPA referiram-se a uma família que tinha clareza sobre suas regras e apoio diante das dificuldades. Entre 30 usuários de drogas, 21 afirmaram a importância de uma família "bem resolvida" para evitar o envolvimento com psicotrópicos, sendo o bom relacionamento entre figuras parentais um fator de proteção. A pesquisa com estudantes com uso pesado de álcool e de outras drogas demonstrou um relacionamento ruim do jovem com seus pais e desarmonia entre pai e mãe.

Também quanto à dinâmica da família do dependente químico, Schenker e Minayo (2004) mencionam que os jovens copiam o comportamento de uso dos familiares. Minuchin (1990) e Bittencourt (2003) atribuem, respectivamente, à ausência da função normativa e ao declínio da figura de autoridade na contemporaneidade, a responsabilidade pelo comportamento drogadito. Para eles, tais fatores explicam as dificuldades parentais em dar limites e orientar os filhos.

Como há autores que pressupõem que a dependência de SPA se dá num meio facilitador, Zampieri (2004) propõe o termo codependente para designar a pessoa que convive diretamente com um dependente químico, havendo um jogo de comportamentos mal adaptativos e compulsivos, aprendidos na convivência familiar. Trata-se de uma experiência recursiva na qual se estabelecem jogos relacionais reveladores de estratégias de manutenção do equilíbrio do sistema familiar. A autora afirma que, geralmente, a infância de um codependente foi difícil, com inversão de papéis parentais, tendo de cuidar de si e de outros desde muito cedo, aprendendo um padrão de funcionamento que demanda cuidados e controle para sua sobrevivência-padrão que tende a ser repetido no futuro, pois se a pessoa só aprendeu a 'cuidar', para ser reconhecida precisará de alguém que demande cuidados.

Embora possamos entender que o abuso de drogas encontra, na família, um momento fundamental de explicação, ele remete a muitos outros contextos e processos que vão muito além dos limites familiares. A partir do pensamento complexo, podemos ampliar a compreensão desse processo. Primeiramente, não é conveniente considerar separadamente família, indivíduo, cultura, economia e avanços tecnológicos, entre outros, ao abordar a questão. A família considerada recursivamente é produto e geradora de uma sociedade-pautada pelo individualismo e pelo consumo - na qual o uso de SPA é prática corrente. Assim, maneiras de intervir na constituição de um sujeito contemporâneo têm, na família, parte e totalidade, o que impõe a condição de considerar continuamente articulações em rede que se processam nas experiências globais.

Observamos que algumas intervenções recentes ampliaram o enfoque, incluindo outros membros da rede social do dependente químico (Ceconello \& Koller, 2003). Para os casos de drogadição, a literatura tem apontado que a terapia familiar e de casal produz melhor desfecho, quando comparada com tratamentos que não incluem as famílias, pois a abordagem familiar propõe a inserção de redes de apoio que poderão auxiliar na descoberta dos recursos emancipatórios (Steinglass, 1987; Stanton \& Todd, 1998; Baptista, Cruz \& Matias, 2003; Molina, 2008; Rocha Brasil, 2008).

\section{A trama das redes sociais na drogadiçáo}

O histórico da abordagem com redes sociais remete a programas inovadores da psiquiatria pósguerra, nos anos 1950, cujo objetivo estava voltado para a desospitalização de pacientes psiquiátricos, com retorno às famílias de origem, amigos e outros integrantes da rede. Assim, o sujeito passa a ser compreendido como parte de uma cadeia de relações e informações. Nessa perspectiva, a necessidade do trabalho com a família sai da esfera clínica para o contexto institucional. Ao explorar a rede social, ampliam-se as possibilidades de se tornarem visíveis as potencialidades de recursos que podem ser ativados, integrando-os, preservando a autonomia das partes com uma corresponsabilidade construída por meio do diálogo (Olinda, 2002). 
Entendemos que a relação sujeito-droga deve ser compreendida como integrada a um interjogo social, político, cultural e subjetivo, numa perspectiva de historicidade não linear (Neubern, 2003). Ao refletir sobre rede social, referimo-nos a todos os vínculos interpessoais de um sujeito: sua família nuclear, sua família extensa, as relações de trabalho, de estudo, de vínculos com serviços de saúde, de alguma inserção comunitária e práticas sociais. Sendo assim, a rede social é uma instância necessária para desenvolver um trabalho no campo da saúde mental.

A pobreza relativa de relações sociais constitui um fator de risco para a saúde. As doenças, principalmente as crônicas, podem gerar um efeito aversivo na rede, estimulando condutas evitativas, aumentando o esgotamento e reduzindo o comportamento de reciprocidade. Sluzki (1997) revela que uma doença afeta e é afetada pela rede social, produzindo impacto nas interações entre os indivíduos. Uma doença prolongada pode deteriorar a qualidade das interações, reduzindo o tamanho e o acesso à rede. Esse impacto pode aumentar sua retração.

A rede social, para Sluzki (1997), exerce algumas funções essenciais, tais como:

a) companhia social, que facilita a reconstrução dos sentidos e transmissão cultural pela reciprocidade da relação. A maioria dos dependentes químicos mora com outra(s) pessoa(s), o que leva a questionar a reciprocidade na relação, pois é comum a queixa ficar paralisada no comportamento do drogadito, mantendo-o no papel de "problema da família";

b) apoio emocional, que se refere ao intercâmbio de atitudes emocionais de compreensão, atingindo diretamente a autoestima das pessoas envolvidas. Muitas vezes, os comportamentos de uma pessoa intoxicada são agressivos ou de distanciamento dos membros da sua rede, enquanto que a família/rede pode também se afastar;

c) guia cognitivo e conselheiro, por meio do qual se compartilha informações pessoais e sociais, esclarecendo expectativas e modelos de papéis. $\mathrm{Na}$ perspectiva recursiva, os papéis podem estar rígidos e representar o funcionamento que produz e se reproduz na drogadição. Por sua vez, os recursos de saúde e potencialidades depositados num só membro podem ser explorados, a partir da perspectiva hologramática, nos outros participantes da rede;

d) regulação social, que estabelece acordos e normas de convivência, reafirmando as responsabilidades de cada um. Por mais que se deseje ou tente pôr em prática as normas de convivência, nos casos de drogadição estes acordos formais podem ser esvaziados pelo dependente químico, na busca de satisfação de seu impulso, ou da família, ao tentar manter o status quo da existência de um membro problemático. Além disso, os processos de fragmentação aprendidos com o projeto da modernidade afastam da compreensão do fenômeno e da construção de relações solidárias;

e) ajuda material e de serviços que contribui com conhecimentos especializados ou ajuda física, oferece suporte social. Por vezes, o dependente químico necessita ser sustentado até se reorganizar emocional e financeiramente, assim como os serviços da rede social podem auxiliar nos processos pertinentes ao tratamento;

f) acesso a contatos que possibilitem conexão com outras pessoas/redes, ampliando possibilidades de transformar funções sociais, uma vez que é recorrente o isolamento do toxicômano e da sua família. É importante haver a possibilidade de eles entrarem em contato com outras pessoas que compartilham esse problema, ampliando alternativas de solução e apoio emocional.

Como a realidade social se constrói na interação, podemos estimular a formação de redes. Essas favorecerão a resolução de problemáticas comuns e a compreensão de que o problema de um é o de um grupo nas mesmas contradições (Dabas, 2001).

Desse modo, deve-se entender a terapia familiar e de redes sociais como um espaço dialógico para articular as possíveis e necessárias relações existentes para a manutenção da drogadição. Levamos em consideração tanto o contexto social 
de um indivíduo, ressaltando a responsabilidade de uma pessoa por si própria e pelos outros, quanto a criação de um espaço em que se permita o máximo de mobilização da característica própria da rede de auto-organização. Consiste em restituir à rede social sua autoria (Aun, Coelho \& Vasconcellos, 2005). É por meio do relacionamento com outras pessoas com a mesma problemática, por vezes no espaço terapêutico, que se dá o intercâmbio de dificuldades e de soluções de problemas, num verdadeiro efeito de rede. Além da ajuda mútua, Ravazzola, Barilari \& Mazieris (1997) ressaltam a potencialização e identificação de aspectos até então desconhecidos, oportunizando a revisão de conceitos e busca de alternativas

Ao ativar a rede de serviços, novas redes são acionadas, as quais adquirem caráter, às vezes, central, por sua capacidade de apoio instrumental emocional (Olinda, 2002). A intervenção em rede permite que se busque possibilidades para autocorrigir ações; para valorizar a palavra e testemunhos dos participantes; para proporcionar contato pessoal direto entre os participantes; para valorizar cada pergunta e a criatividade; considerar as diferenças como possibilidades de crescimento; respeitar os direitos e os limites de cada um; possibilitar articulações; aceitar a multiplicidade e aproveitar os erros para aprendizagem (Ravazzola et al. 1997).

A abordagem em redes sociais tem sido ponto de apoio para o planejamento, execução e gestão de políticas públicas. Um estudo fez uma revisão crítica das pesquisas sobre intervenções familiares, reforçando que trazem resultado positivo para o usuário, sua família e a rede social (Molina, 2008). Este estudo observou, ainda, que o maior desafio está na implementação desse tipo de intervenção na rotina de tratamentos para a drogadição. Ressalta, por fim, a necessidade das políticas concentrarem-se na disseminação de abordagens familiares e na sua integração como coparticipantes dos tratamentos existentes, pois acreditamos ser necessário transcender os limites do indivíduo e da família, para incluir o ecossistema e articular com as políticas públicas.

\section{As políticas públicas voltadas à drogadiçáo}

Entendemos as políticas públicas como esforços e recursos investidos pelo Estado, por meio de decisões de consenso tomadas por governantes na forma de leis, regras ou regulações. O consenso implica em decisões que se embasam em evidências documentadas a ponto de haver concordância entre especialistas e autoridades da área, em prol do interesse público. As evidências científicas são necessárias, principalmente para quem elabora os programas, pois podem facilitar a avaliação de estratégias disponíveis e familiarizar o profissional da saúde, principalmente de saúde mental, com o trabalho realizado (Brasil, 2005).

O atual fluxo das políticas públicas segue como uma pirâmide: no seu topo estão os responsáveis pelo planejamento e decisões e com recursos para a realização das diretrizes; no meio, encontram-se os técnicos responsáveis pela execução e implementação de um programa já elaborado; e na base, existem os numerosos usuários do programa, os que "recebem" a política (Aun, Coelho \& Vasconcellos, 2005).

Porém, há contradições que se expressam nas instituições voltadas para o problema da drogadição, principalmente aquelas ligadas às estruturas de governo. Bravo (2003) aponta a disputa por espaços referindo a existência de dois lados. O primeiro volta-se às políticas ligadas à repressão, que avançam sobre o campo da prevenção e tratamento ao definir os consumidores de SPA ora como marginais, ora como doentes, num discurso contraditório entre penalização e tratamento. O outro lado aponta a dificuldade das instituições de saúde, educação e assistência social assumirem sua função, reproduzindo esse discurso que discrimina, sem delimitar espaço teórico e de trabalho próprio. $\mathrm{O}$ autor denuncia a dimensão política que impõe crescimento ou retrocesso de discursos e projetos, associados a interesses setoriais ou eleitorais.

Para identificar a oficialidade para o problema da drogadição, este artigo retoma as propostas do Sistema Único de Saúde (SUS), o qual foi concebido como um conjunto de ações e serviços de saúde que objetiva a promoção de maior qualidade de vida para toda a população brasileira. Uma de suas grandes inovações é a noção de saúde como um direito de cidadania, inédita na história das políticas brasileiras. Dentre suas principais propostas estão a universalidade de acesso aos serviços de saúde, integralidade e igualdade de assistência, descentralização políticoadministrativa, capacidade de resolução dos serviços e a participação da comunidade (Brasil, 1988).

Retomamos, ainda, o Sistema Único de Assistência Social (SUAS), resultado da reformulação 
da Assistência Social no Brasil, a partir da Constituição Federal de 1988, como sendo política pública não contributiva, pautada pela universalidade da cobertura e do atendimento, ao lado da Saúde (não contributiva) e da Previdência Social (contributiva). A Assistência Social é um dever do Estado e um direito de quem dela necessitar (Brasil, 2002).

Dentre as tentativas de regularização social do problema da drogadição, em agosto de 2006 foi sancionada a Lei n. 11.343 (Brasil, 2006a). A nova legislação substituiu as leis anteriores, contemplando alguns avanços, principalmente no que se referia à exclusão da pena de prisão para o usuário de drogas, aproximando o uso de SPA de uma questão de saúde pública e afastando da esfera policial. Sendo assim, o maior desafio passou a ser a ampliação dos serviços públicos de saúde do SUS, esforço que deve ser responsabilidade do Ministério da Saúde e das Secretarias Estaduais e Municipais de Saúde.

Foi, então, instituído o Sistema Nacional de Políticas Públicas sobre Drogas (SISNAD), que tem por finalidade articular, integrar, organizar e coordenar as atividades relacionadas com a prevenção do uso indevido, atenção e reinserção social de usuários e dependentes de drogas, bem como a repressão da produção não autorizada e do tráfico ilícito de drogas. Integram o SISNAD: o Conselho Nacional Antidrogas (CONAD), órgão normativo e de deliberação coletiva do sistema, vinculado ao Gabinete de Segurança Institucional da Presidência da República; a Secretaria Nacional Antidrogas (SENAD), na qualidade de secretaria-executiva do colegiado; o conjunto de órgãos e entidades públicos que exerçam atividades referentes ao problema da drogadição; o Poder Executivo Federal; os Estados, os Municípios e o Distrito Federal; e as organizações, instituições ou entidades da sociedade civil que atuam nas áreas da atenção à saúde e da assistência social e atendem usuários ou dependentes de drogas e respectivos familiares.

Dentre as diretrizes da SENAD encontramse: promover e garantir a articulação e integração em rede nacional das intervenções para tratamento, recuperação, redução de danos, reinserção social e ocupacional (Unidade Básica de Saúde, ambulatórios, Centro de Atenção Psicossocial, Centro de Atenção Psicossocial Álcool e Drogas, comunidades terapêuticas, grupos de auto-ajuda, hospitais gerais e psiquiátricos, hospital-dia, serviços de emergências, corpo de bombeiros, clínicas especializadas, casas de apoio e convivência e moradias assistidas) com o SUS e SUAS para o usuário e seus familiares, por meio de distribuição descentralizada e fiscalizada de recursos técnicos e financeiros.

O CONAD propõe, ainda, que o acesso às diferentes modalidades de tratamento e recuperação, reinserção social e ocupacional deve ser identificado, qualificado e garantido como um processo contínuo, para os usuários, dependentes e seus familiares, com investimento técnico e financeiro de forma descentralizada. As ações devem ser vinculadas a pesquisas científicas, avaliando-as e incentivando-as e multiplicando aquelas que tenham obtido resultados mais efetivos (Brasil, 2006b).

As instituições de todo o país cadastradas no SENAD dividem-se em governamentais e não governamentais, as quais prestam serviços de prevenção, tratamento, redução de danos, ensino e pesquisa na área da drogadição. Apesar de toda esta organização, a política do Ministério da Saúde para a atenção integral a usuários de álcool e outras drogas reconhece um "atraso histórico" do SUS em relação às políticas públicas para a drogadição, indicando "a necessidade de uma ação não apenas ampliada, mas para onde devem concorrer diferentes saberes e aportes teórico-técnicos" (Brasil, 2003,p. 7). Aponta, ainda, para uma perspectiva transversalizadora, diversificada em ofertas terapêuticas, preventivas, reabilitadoras, educativas e promotoras da saúde que permitam reconhecer o usuário, suas necessidades e vínculos com seus familiares. Essa política indica o paradigma de Redução de Danos como estratégia de saúde pública que visa a diminuir os prejuízos causados pela drogadição. A Redução de Danos reconhece o usuário na sua singularidade, sem julgamento, com corresponsabilidade entre ele e o agente de saúde. Aponta, ainda, fatores de risco e proteção familiar, os quais seriam facilitadores ou impeditivos para o uso de drogas. Como fator de risco menciona o uso de álcool pelos pais, isolamento social entre os membros da família, padrão familiar disfuncional, falta do elemento paterno; como fator de proteção, cita vinculação familiar, cultivo de valores e tarefas domésticas partilhadas.

A política do Ministério da Saúde propõe, também, a regulamentação de Comunidades Terapêuticas, as quais se multiplicaram em virtude do "vazio de possibilidades para a reabilitação das pessoas com dependência ao álcool ou a outras drogas" (Brasil, 2003, p. 46). Essa modalidade de 
tratamento define a drogadição como doença e o trabalho terapêutico é focado na abstinência. Há, ainda, articulação com os grupos de mútua-ajuda. Outro modelo é o de assistência em saúde mental, redefinido em redes de atenção especializadas e compostas por dispositivos extra-hospitalares, tais como o serviço de atenção psicossocial para atendimento de pacientes com transtornos decorrentes do uso de substâncias psicoativas para o problema de álcool e drogas (CAPSad).

Todavia, Bravo (2003) aponta que essas inúmeras propostas, iniciativas e avaliações recorrentes ainda não se tornaram eficazes diante da enorme dimensão do problema. Pode-se ainda questionar a ideia de que esse tema possa ser abordado por uma área exclusiva, sendo necessário incorporar elementos próprios de outros campos do saber: sociologia, antropologia, economia, política ou direito. Percebemos políticas ineficazes que realizam estratégias compensatórias no enfrentamento de necessidades, num funcionamento voltado para soluções imediatas que pouco ajudam, visto que não preparam as famílias para uma emancipação, mas as perpetuam num ciclo de dependência de ações fragmentadas. Por fim, as diretrizes das políticas oficiais, ao se apresentarem numa instância teórica, dificultam a integração com as práticas profissionais. Propomos a dialógica entre as instâncias que se mostram antagônicas e separadas, pensando em sistemas complexos com múltiplas interações e retroações.

\section{Consideraçóes finais}

Essas reflexões encaminham para o pensamento complexo. Navarro (2006) propõe o conceito 'holograma social', para se referir às realidades sociais humanas que se compõem de unidades - sujeitos individuais que interagem entre si, são construídos por e constroem essas realidades com sucessivos níveis recursivos. Numa perspectiva hologramática, percebemos diversas facetas que se apresentam como parte do problema atual com drogas, as quais implicam diversas contradições e desafios, revelando seu caráter complexo, num mosaico em que o dependente químico, sua família, a rede social, os trabalhadores de saúde mental, pesquisadores, o contexto social atual, todos se mostram com dificuldades de lidar com a situação, necessitando de cuidados e atenção.
O pensamento complexo propõe um desafio que incita a novas formas de pensar e agir, pois é fácil usar as premissas que já temos e em que nos apoiamos; difícil é mudar os pontos de partida já conhecidos do raciocínio (Vasconcellos, 2008). O reconhecimento da incerteza pode ser desencorajador e estimular um pensamento redutor. Apesar de proporcionar segurança pelo conhecido, esse mesmo pensamento redutor implica políticas sociais redutoras que terminam por se mostrar inoperantes (Almeida, 2006). O pensamento complexo propõe manter as diferenças e fazer com que, dialogicamente, estes antagonismos comuniquem-se e proponham novas formas de se relacionar, libertadoras das potencialidades humanas e, certamente, originárias de problemas para reflexão, de antagonismos, de construção de espaços de dialógicas e alternativas.

\section{Agradecimentos}

Agradecemos a colaboração subsidiada pela CAPES pela concessão da bolsa que possibilitou a realização do mestrado que frutificou neste trabalho.

\section{Referências}

Almeida, M. (2006). Complexidade, do casulo à borboleta. In G. Castro, E. Carvalho, \& M. Almeida (Org.). Ensaios de complexidade (pp. 25-45). Porto Alegre: Sulina.

Aun, J., Coelho, S., \& Esteves V.M.J. (2005). Atendimento de famílias e redes sociais: Fundamentos teóricos e epistemológicos. Belo Horizonte: Ophicina Arte \& Prosa.

Baltieri, D. A., \& Focchi, G. R. A. (2001). Tratamentos farmacológicos das dependências de álcool, cocaína e opióides. Jornal Brasileiro de Dependência Química, 2(supl. 1), 7-11.

Baptista, M., Cruz, M., \& Matias, R. Drogas e pósmodernidade: Prazer, sofrimento, tabu. Rio de Janeiro: Ed. UERJ.

Bauman, Z. (2001). Modernidade líquida. Rio de Janeiro: Jorge Zahar.

Bertolote, J. M., \& Ramos, S. P. (1997). Alcoolismo hoje. Porto Alegre: Artes Médicas. 
Bittencourt, L. (2003). O rei está nu: um dos avatares da função paterna na sociedade contemporânea. In M. Baptista, M. Cruz, \& R. Matias (Org). Drogas e pós-modernidade: Prazer, sofrimento, tabu (pp. 97-109). Rio de Janeiro: Ed. UERJ.

Brasil. (1988). Constituição Federal de 1988. Título VIII: Da ordem social. Capítulo II - Seção II, Saúde-Artigos 196; 197; 198, Parágrafo Único Ec 29:200.

Brasil. (2002). Portaria 336 de 19 de fevereiro de 2002. Recuperado em 25 jun. 2007, em http://portal. saude.gov.br/saude/visualizar_texto.cfm?idtxt= 17148

Brasil. (2003). A Política do Ministério da Saúde para atenção integral a usuários de álcool e outras drogas. Brasília: Ministério da Saúde. Recuperado em 22 jun. 2007, em http://portal.saude.gov.br/saude/ visualizar_texto.cfm?idtxt $=17148$

Brasil. (2005). Política Nacional sobre Drogas, aprovada pelo Conselho Nacional Antidrogas. Recuperado em 27 out. 2005, em http://www.obid.senad. gov.br/portais/OBID/biblioteca/documentos/ Legislacao/326979.pdf

Brasil. (2006a). Lei no 11.343, de 23 de agosto de 2006. Recuperado em jun. 2007, em http://portal.saude. gov.br/saude/

Brasil. (2006b). Política Nacional sobre Drogas, aprovada pelo Conselho Nacional Antidrogas. Recuperado em 27 out. 2007 em http:/ / portal.saude.gov.br/saude/

Bravo, O. A. (2003). Discurso sobre drogas nas instituições públicas do DF. In M. Baptista, M. Cruz, \& R. Matias (Org). Drogas e pós-modernidade: Prazer, sofrimento, tabu (pp. 267-277). Rio de Janeiro: Ed. UERJ.

Bucher, R. (1996). Drogas e sociedade nos tempos da AIDS. Brasilia: Editora Universidade de Brasília.

Carlini, E. A., Galduróz, J. C., Nappo, S., \& Noto, A. R. (2005). II Levantamento domiciliar sobre o uso de drogas psicotrópicas no Brasil. Recuperado em junho/2008, em http://www.unifesp.br/dpsicobio/ cebrid/levantamento_brasil/parte_1.pdf

Cecconello, A. M., \& Koller, S. H. (2003). Inserção ecológica na comunidade: Uma proposta metodológica para o estudo de famílias em situação de risco. Psicologia Reflexão e Crítica, 16(3), 515-524.
Cirillo, S., Berrini, R., Cambiaso, G., \&Mazza, R. (1999).La família del toxicodependente. Buenos Aires: Paidós.

Craig, R. (1991). Abuso de substâncias. In R. J. Craig (Org.). Entrevista clínica e diagnóstica. Porto Alegre: Artes Médicas.

Dabas, E. N. (2001). Red de redes: Las prácticas de la intervención en redes sociales. Buenos Aires: Paidós.

Edwards, G., \& Dare, C. (1999). Psicoterapia e tratamento de adições. Porto Alegre: Artes Médicas.

Escohotado, A. (1994). Las drogas: De los orígenes a la prohibicion. Madrid: Alianza.

Feix, R. (1996). Drogas: Uso, abuso e dependência. In B. B. Duncan, M. I. Schmidt, \& E. R. J. Giugliani (Org.). Medicina ambulatorial: Condutas clínicas em atenção primária (pp. 537-550). Porto Alegre: Artes Médicas.

Gonçalves, G., Delgado, S., \& Garcia, C. (2003). A toxicomania e a busca da felicidade na sociedade de consumo. In M. Baptista, M. Cruz, \& R. Matias, (Org.). Drogas e pós-modernidade: Prazer, sofrimento, tabu (pp. 119-128). Rio de Janeiro: Ed. UERJ.

Horta, R. (2003). As famílias e as drogas na contemporaneidade. In P. Guareschi, A. Pizzinato, L. L. Krüger, \& K. Macedo (Org.). Psicologia em questão: Reflexões sobre a contemporaneidade (pp. 201215). Porto Alegre: EDIPUCRS.

MacRae, E. (2001). Antropologia: Aspectos sociais, culturais e ritualísticos. In S. Seibel, \& A.Toscano Jr. Dependência de drogas (pp. 25-34). São Paulo: Atheneu.

Minayo, M. C. (2003). Sobre a toxicomania da sociedade. In M. Baptista, M. Cruz, \& R. Matias (Org.). Drogas e pós-modernidade: Faces de um tema proscrito (pp. 13-29). Rio de Janeiro: Ed. UERJ.

Minuchin, S. (1990). Famílias: Funcionamento e tratamento. Porto Alegre: Artes Médicas.

Molina, T. (2008). Birmingham and solihull substance misuse services and senior lecturer, school of psychology, the University of Birmingham. Recuperado em 15 jul. 2008, em www.unifesp.br

Morin. E. (1998). Ciência com consciência (2a ed.). Rio de Janeiro: Bertrand. 
Morin, E. (2005). O método 2: A vida da vida (3a ed.). Porto Alegre: Sulina.

Morin, E. (Org.). (2007). A religação dos saberes: O desafio do Século XXI. Rio de Janeiro: Bertrand Brasil.

Navarro, P. (2006). Holograma social. In G. Castro, E. Carvalho, \& M. Almeida (Org.). Ensaios de Complexidade (4a ed.). Porto Alegre: Sulina.

Neubern, M. (2003). Contribuições de uma epistemologia complexa para drogadição. In M. Baptista, M. Cruz, \& R. Matias (Org.). Drogas e pós-modernidade: Prazer, sofrimento, tabu (pp. 253-265). Rio de Janeiro: Ed. UERJ.

Olinda, E. (2002). Rede social de apoio à família. In Terra dos Homens (Org.). Cuidar de quem cuida: Reintegração familiar de crianças e adolescentes em situação de rua (pp. 47-57). Rio de Janeiro: Booklink.

Ravazzola, M. C., Barilari, S., \& Mazieres G. (1997). A família como grupo e o grupo como família. In D. Zimermn, \& L. C. Osório (Org.). Como trabalhamos com grupos (pp. 14-17). Porto Alegre: Artes Médicas.

Rocha Brasil, V. (2008). Família e drogadição. In C. Cerveny (Org.). Família e... comunicação, divórcio, mudança, resiliência, deficiência, lei, bioética, doença, religião e drogadição (pp. 85-98). São Paulo: Casa do Psicólogo.

Saraiva, J. E. M. (2000). Do individualismo moderno ao narcisismo contemporâneo: A produção da subjetividade na cultura do consumo In S. Souza (Org.). Subjetividade em questão: A infância como crítica da cultura (pp. 47- 64). Rio de Janeiro: 7 letras.

Schenker, M., \& Minayo, M. C. S. (2004). A importância da família no tratamento do uso abusivo de drogas: uma revisão da literatura. Cadernos de Saúde Pública, 20(3), 3-8.

Seibel, S., \& Toscano Jr. A. (2001). Dependência de drogas. São Paulo: Atheneu

Sluzki, C. E. (1997). A rede social na prática sistêmica. São Paulo: Casa do Psicólogo.

Stanton, M.D., \& Todd, T.C. (Org.). (1988). Terapia familiar del abuso y adiccion a las drogas. Barcelona: Gedisa.

Steinglass, P. (1987). La familia alcohólica. Barcelona: Gedisa.
Vasconcellos, M. J. (2008). Pensamento sistêmico: O novo paradigma da ciência ( $7 \mathrm{a}$ ed.). Campinas: Papirus.

Zampieri, M. A. (2004). Co-dependência: O transtorno e a intervenção em rede. São Paulo: Ágora.

Zemel, M. L. (2001). O papel da família no tratamento da dependência. Revista Imesc, (3), 43-63. Recuperado em 13 jul. 2008, em http://www. imesc.sp.gov.br/pdf/artigo $\% 203 \% 20-\% 200 \% 20$ PAPEL $\% 20$ DA $\% 20$ FAM $\%$ C 3\%8DLIA $\% 20$ N O \% 20 TR A T A M EN T O \% 20 D A \% 20 DEPEND $\%$ C3\%8ANCIA.pdf

Zimerman, D., \& Osório, L. (Org.). (1997). Como trabalhamos com grupos. Porto Alegre: Artes Médicas.

Recebido: 25/06/2008 Received: 06/25/2008

Aprovado: 30/10/2009 Approved: 10/30/2009 